Article

\title{
Novel Nozzle Shapes for Synthetic Jet Actuators Intended to Enhance Jet Momentum Flux
}

\author{
Jozef Kordík * and Zdeněk Trávníček \\ Institute of Thermomechanics of the Czech Academy of Sciences, Dolejškova 5, 18200 Prague, Czech Republic; \\ tr@it.cas.cz \\ * Correspondence: kordik@it.cas.cz; Tel.: +420-266-053-483
}

Received: 27 July 2018; Accepted: 25 August 2018; Published: 28 August 2018

\begin{abstract}
An axisymmetric synthetic jet actuator based on a loudspeaker and five types of flanged nozzles were experimentally tested and compared. The first (reference) type of nozzle was a common sharp-edged circular hole. The second type had a rounded lip on the inside. The third nozzle type was assembled from these two types of nozzles-it had a rounded lip on the inside and straight section on the outside. The fourth nozzle was assembled using orifice plates such that the rounded lips were at both inner and outer nozzle ends. The last nozzle was equipped with an auxiliary nozzle plate placed at a small distance downstream of the main nozzle. The actuators with particular nozzles were tested by direct measurement of the synthetic jet (SJ) time-mean thrust using precision scales. Velocity profiles at the actuator nozzle exit were measured by a hot-wire anemometer. Experiments were performed at eight power levels and at the actuator resonance frequency. The highest momentum flux was achieved by the nozzle equipped with an auxiliary nozzle plate. Namely, an enhancement was approximately $31 \%$ in comparison with an effect of the reference nozzle at the same input power. Furthermore, based on the cavity pressure and the experimental velocity profiles, parameters for a lumped element model (mass of moving fluid and pressure loss coefficient) were evaluated. These values were studied as functions of the dimensionless stroke length.
\end{abstract}

Keywords: synthetic jet; synthetic jet actuator; momentum flux; jet thrust; nozzle shape

\section{Introduction}

Synthetic jets (SJs) are fluid flows created by fluid pulsations and are formed in free space behind a nozzle [1]. The fluid is periodically pushed and pulled through the nozzle with one end exiting into a cavity. The source of the pulsations is an oscillating diaphragm that bounds one side of the cavity. The nozzle is the only inlet/outlet into/out of the cavity; therefore, the time-mean mass flux through the nozzle is zero. This is why SJs are often referred to as zero-net-mass-flux jets [2]. The momentum flux along the nozzle axis, however, is non-zero. It causes the flow to continue downstream of the nozzle exit, forming a jet flow similar to the continuous jet.

Since the end of the last century, SJs have been intensively investigated and many potential applications have been proposed. The applications have been found in boundary-layer separation control [3-9] jet vectoring [10,11], and heat transfer enhancement [12-15]. A variant of the SJ, namely the non-zero-net-mass-flux jet (or hybrid SJ), has been investigated more recently [16-19].

For the synthetic jet actuators (SJA) based on elastic diaphragms (e.g., based on a loudspeaker or a piezoceramic membrane), when an energy balance is considered, the most advantageous operating conditions are found at resonance. Therefore, many studies focused on location and prediction of the SJ actuator resonance characteristics [20-25]. With an SJ actuator operated at resonance, other ways to enhance the exploitable outlet quantities, such as the jet thrust, still exist. 
An augmentation of the jet thrust is the main topic of this work. Specifically, this paper investigates the axisymmetric SJ actuators based on a loudspeaker operating at the first resonance. Under these conditions, five types of flanged nozzles were tested within the actuator. The first nozzle was a common sharp-edged circular hole. The remaining nozzles combined rounded lips at the nozzle ends. An auxiliary nozzle plate placed slightly downstream of the main nozzle exit was tested, as well. The nozzles were designed to decrease the hydraulic resistance and, therefore, enhance the resulting jet momentum flux (jet thrust). Using the SJ time-mean thrust measurement, the most effective nozzle design was determined.

\section{Problem Parameters}

\subsection{Basic Synthetic Jet Dimensionless Parameters}

A harmonically driven SJ can be quantified by two dimensionless parameters, which include the Reynolds number, $R e$, and the dimensionless stroke length, $L_{0} / D_{\mathrm{n}}$. The definitions of these parameters are as follows:

$$
R e=\frac{U_{0} D_{\mathrm{n}}}{v}, \frac{L_{0}}{D_{\mathrm{n}}}=\frac{U_{0}}{f D_{\mathrm{n}}},
$$

where $D_{\mathrm{n}}$ is the nozzle diameter of the SJA (see Figure $1 \mathrm{a}, \mathrm{b}$ and a description in Section 3.1), $f$ is the driving frequency of the actuator's harmonic excitation, and $v$ is the kinematic viscosity of the working fluid. The characteristic time-mean velocity is denoted $U_{0}$ in Equation (1) and is defined in the next section.

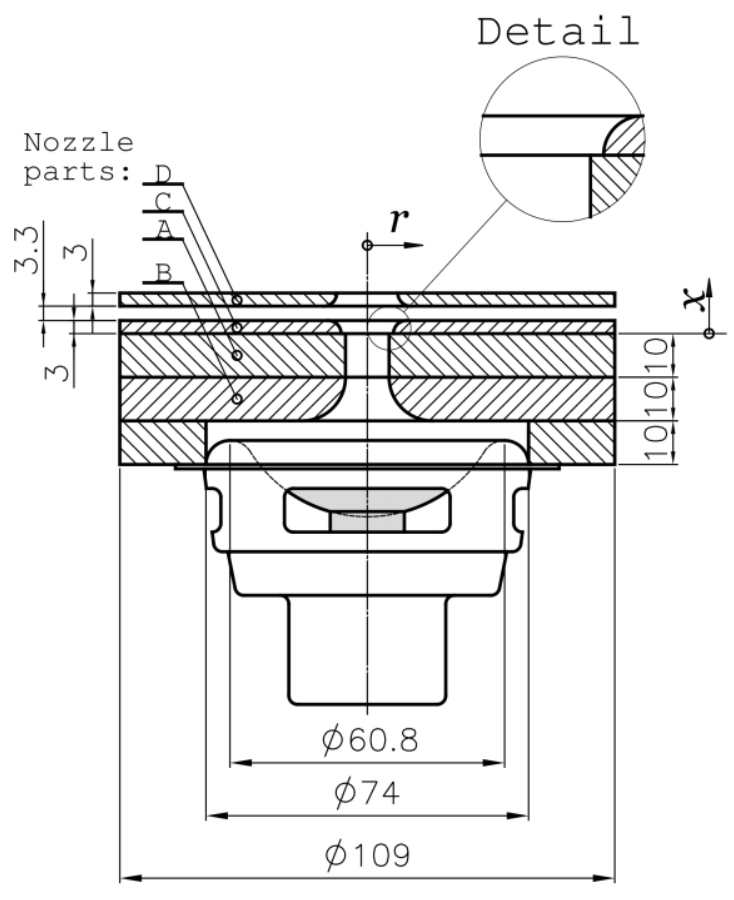

(a)

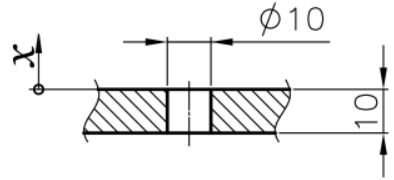

Nozzle B

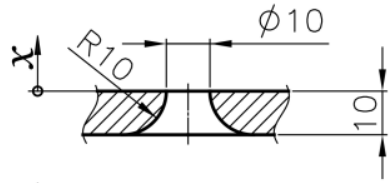

Nozzle AB
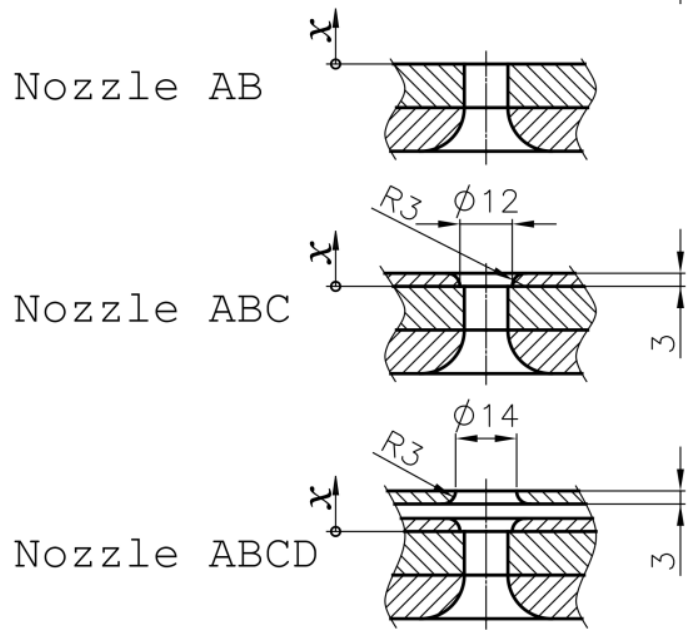

(b)

Figure 1. Experimental setup and methods (dimensions in millimeters): (a) synthetic jet actuator with nozzle ABCD mounted, (b) shapes of the tested nozzles. 


\subsection{Synthetic Jet Integral Quantities}

A basic integral quantity, upon which the Reynolds number and dimensionless stroke length are based, is the SJ characteristic velocity, $U_{0}$. Assuming an axisymmetric $S \mathrm{~J}$, the standard characteristic velocity is defined as follows [1]:

$$
U_{0}=\frac{8}{D_{\mathrm{n}}^{2} T} \int_{0}^{T_{\mathrm{E}}} \int_{0}^{\frac{D_{\mathrm{n}}}{2}} u_{\mathrm{n}}(x=0, r, t) r \mathrm{~d} r \mathrm{~d} t
$$

where $T=1 / f$ is the excitation period, $T_{\mathrm{E}}$ is the extrusion stroke duration, and $u_{\mathrm{n}}$ is the fluid velocity at the nozzle exit cross-sectional area. The phase position of the velocity $u_{\mathrm{n}}$ with respect to the time cycle origin is such that the inner integral of Equation (2) is positive for the whole integration interval $\left(0, T_{\mathrm{E}}\right)$. The indicated cylindrical coordinate system $(x, r)$ is introduced in Figure 1a,b.

The most important observed integral quantity is the SJ time-mean thrust, $M_{0}$, with a magnitude that can be measured directly using precision scales. The experiment assumes a vertical, upward-issuing SJ, with an actuator placed on a precision scale. The action force related to the momentum flux is directed upward, and the reaction force (jet thrust) acting on the scale surface is directed downward and thus the jet thrust is measured. For particular measurement details, see Section 3.2.

Assuming that the velocity profiles are flat along the nozzle diameter (slug flow model) and the nozzle outlet velocity waveform is purely sinusoidal, the measured jet thrust can be used to evaluate the characteristic velocity, $U_{0}$. Based on Equation (2), the velocity can be then approximated by the following formula [26,27]:

$$
U_{0}=\frac{2}{\pi} \sqrt{\frac{4 M_{0}}{\rho \pi D_{\mathrm{n}}^{2}}},
$$

where $\rho$ is the working fluid density. The velocity $U_{0}$ obtained from Equation (3) was used to evaluate dimensionless stroke length according to Equation (1).

\subsection{Parameters for Lumped Element Model}

Lumped parameter models are often used to predict SJ outlet velocities or SJA optimized geometries [28-30]. Basic momentum equations of a SJA, which are based on lumped element approximation, have the following form [31]:

$$
\begin{aligned}
& m_{\mathrm{d}} \dot{u}_{\mathrm{d}}=-K_{\mathrm{d}} x_{\mathrm{d}}-p_{\mathrm{c}} S_{\mathrm{d}}-B_{\mathrm{d}} u_{\mathrm{d}}+F(t), \\
& m_{\mathrm{n}} \dot{u}_{\mathrm{n}}=S_{\mathrm{n}}\left(p_{\mathrm{c}}-\xi \frac{\rho u_{\mathrm{n}}\left|u_{\mathrm{n}}\right|}{2}\right),
\end{aligned}
$$

where $m_{\mathrm{d}}$ is the diaphragm mass, $K_{\mathrm{d}}$ is its spring constant, $S_{\mathrm{d}}$ is the diaphragm effective cross-sectional area, $B_{\mathrm{d}}$ is its damping and $F(t)$ is the force, which excites the diaphragm oscillation. The diaphragm velocity and the velocity of the fluid inside the nozzle with cross-sectional area $S_{\mathrm{n}}$ are denoted as $u_{\mathrm{d}}$ and $u_{\mathrm{n}}$, respectively. The pressure difference between the cavity and ambiance is denoted as $p_{\mathrm{c}}$. The $m_{\mathrm{n}}$ denotes the mass of the moving fluid inside and within the vicinity of the nozzle; $\xi$ is the pressure loss coefficient across the cavity-nozzle-ambiance. These two parameters $\left(m_{\mathrm{n}}\right.$ and $\left.\xi\right)$ are unique for each of the tested nozzles and were obtained from measurements.

\section{Measurement Methods}

\subsection{The Synthetic Jet Actuator}

Figure 1a shows a schematic view of the tested SJA that was operated with air as the working fluid (for fluid properties, see Table 1). The actuator was based on an Aurasound NS3-193-8A loudspeaker with a harmonically driven diaphragm producing pressure oscillations in the cavity. Five axisymmetric 
nozzles were tested as seen in Figure 1b. The narrowest diameter within each of the tested nozzles was consistently $D_{\mathrm{n}}=10.0 \mathrm{~mm}$.

- The first (reference) nozzle was assigned as nozzle A, which was a standard flanged and sharp-edged nozzle with length equal to diameter. From different point of views, such nozzle types were studied within [28-30,32,33].

- Nozzle B was designed with an inner rounded lip having radius equal to the nozzle length; also, this type of nozzle was tested by other authors, see e.g., [32,34,35].

- Nozzle AB was a combination of the previous nozzles. Note that an experimental study of similar nozzle geometries was done, e.g., by Nani and Smith [32].

- The fourth nozzle was denoted as ABC (it consists of three nozzle plates $A+B+C$, see Figure $1 \mathrm{a}$ ) and had a special novel design with rounded lips at both inner and outer nozzle ends. A similar shape was tested by Lee and Goldstein [36] for a slot-type nozzle. However, this study's nozzle was circular and equipped with a small step at the end of the straight nozzle section. This step promoted flow separation and prevented flow reattachment during extrusion stroke.

- The ABCD nozzle combined the design by Rylatt and O'Donovan [37] with the ABC nozzle. The nozzle contained an auxiliary outer nozzle-denoted as part D, see Figure 1a. The auxiliary nozzle had a greater diameter $(12.0 \mathrm{~mm})$ than $D_{\mathrm{n}}=10.0 \mathrm{~mm}$ and was placed $3.3 \mathrm{~mm}$ downstream from the exit of nozzle ABC, see Figure 1a. The rounded edge of the part D was oriented towards the actuator outlet, helping to direct the radially dispersed momentum flux along the $x$-axis.

During all experiments, the actuator was supplied with an electric current generated by an Agilent 33220A function generator and amplified by a homemade constant-gain-amplifier. More details of the experiment were presented in [38]. The experimental investigation was performed at eight input power levels between 0.13 and $2.26 \mathrm{~W}$ (for particular power values see Table 1). For each combination of the applied power and the nozzle geometry, the optimum driving frequency was first found with respect to a maximum jet thrust, which was then evaluated using a precision scale.

Table 1. Basic properties of the used synthetic jet actuator (SJA), fluid properties and forcing details.

\begin{tabular}{cccc}
\hline Quantity & Symbol & Value & Unit \\
\hline Synthetic jet actuator & & & \\
Loudspeaker type & & Aurasound NS3-193-8A & $(\mathrm{mm})$ \\
Nozzle diameter & $D_{\mathrm{n}}$ & 10.0 & $(\mathrm{~mm})$ \\
Diaphragm effective diameter & $D_{\mathrm{d}}$ & 0.8 & $(\mathrm{mg})$ \\
Mass of air inside the nozzle volume & $m_{\mathrm{nn}}$ & $0.92,2.1,3.0,3.5,4.1$ & $\left({ }^{\circ} \mathrm{C}\right)$ \\
Fluid: air & & & $(\mathrm{Pa})$ \\
Ambient temperature & $T_{\mathrm{a}}$ & $98.2-26.6$ & $\left(\mathrm{~kg} / \mathrm{m}^{3}\right)$ \\
Barometric pressure & $p_{\mathrm{b}}$ & $1.14-1.15$ & $(\mathrm{~W})$ \\
Density & $\rho$ & & $(\mathrm{Hz})$ \\
\hline Forcing & & $0.13,0.20,0.30,0.45,0.68,1.02,1.53$, and 2.30 & \\
Input real power & $P_{\mathrm{e}}$ & $55-65$ &
\end{tabular}

\subsection{Data Acquisition and Measurement Methods}

\subsubsection{Measurement of the Jet Thrust Using Precision Scales}

Measurements of integral forces is a classical technique in experimental fluid mechanics. It has been employed since the turn of the 19th and 20th centuries in wind tunnel testing. Surprisingly, such measurements in SJ studies are rather rare yet.

Probably the first journal paper which described measurements of integral forces by precision scales for SJA design was presented by Trávníček et al. [39]. Another investigation, which was supported by this method, was presented by Kooijman and Ouweltjes [40]. The method was used by Broučková and Trávníček [26] and a reasonable agreement with the hot-wire velocity data was 
concluded. Another SJ measurement was performed by Trávníček and Broučková [41] for SJA with a bio-inspired actuator with an oscillating nozzle lip. Another investigation of SJs, which employed this method, was performed by Kordík and Trávníček [38].

More recently, the limits and accuracy of this method have been quantified by means of an independent hot-wire measurement and spatial-temporal integration of velocity profiles [42]. It was concluded that the thrust measurements by means of a precision scale yield a very good evaluation of the characteristic velocity, momentum, and kinetic energy fluxes. Namely, the maximum deviations between experimental data obtained by this method and reference hot-wire data have been evaluated [42]:

- For relatively weak SJs at the dimensionless stroke length of $L_{0} / D_{\mathrm{n}}$ from 0.5 to 5 (i.e., including the vicinity of the SJ existence threshold), the maximum deviation is within $\pm 5.4 \%$.

- For stronger SJs at $L_{0} / D_{\mathrm{n}} \geq 5$, the maximum deviation is only $\pm 3.4 \%$.

Following a detailed description of SJ measurements by precision scales [38,42], the SJA was placed on a Mettler Toledo PR8002 DR precision scale with nozzle directing the SJ upward. Before the actuator power input was turned on, the scale was reset. The chosen power input value was adjusted using a regulation loop driven by a personal computer. After adjustment of the power input and stabilization of the time-mean flow, the force (i.e., the seeming mass magnitude increase), due to the SJ time-mean momentum, was measured. The magnitude of SJ time-mean momentum was evaluated according to Newton's third law of motion as follows:

$$
M_{0}=m_{0} g
$$

where $m_{0}$ is the value of the seeming mass due to the reaction force, and $g$ is the magnitude of the gravitational acceleration, $g=9.80665 \mathrm{~m} / \mathrm{s}^{2}$.

To check the desired power input into the actuator, the supplied electric current, $i$, and voltage, $e$, were acquired and sampled using an NI-PCI 6023E data acquisition device. The sampling frequency was $128 \cdot f$, and the number of samples was 25,600 .

The uncertainty of the jet thrust measurement method was evaluated in [38]: based on PR8002 DR precision scale resolution and data floating, the relative uncertainty of the measured thrust values is in the range of $2.8-6 \%$ (at $95 \%$ confidence level).

\subsubsection{Hot-Wire and Cavity Pressure Measurements}

Hot-wire measurement of the velocity profiles occurred at the narrowest neck of the tested nozzles. The velocity profiles were used here to evaluate the lumped model parameters. The velocity readings were measured using the hot-wire probe (55P16, DANTEC) and anemometer (MiniCTA 54T30, DANTEC). The experimental approach was as follows. The desired power level and frequency were tuned within the SJA, and the hot-wire probe was then placed at the nozzle outlet of the running actuator (the approximate probe position was $x=0.3 \mathrm{~mm}$, for the coordinate system, see Figure $1 \mathrm{a}, \mathrm{b}$ ). Afterwards, the probe was traversed along the nozzle diameter. At 17 discrete points, the hot-wire signal from the anemometer was sampled in an NI-PCI 6023E data acquisition device. The settings of data acquisition device were the same as during precision scale experiment, i.e., sampling frequency was $128 \cdot f$, and the number of samples was 25,600 .

Along with velocity data, electric current, $i$, voltage, $e$, cavity pressure, $p_{\mathrm{c}}$, and the temperature of the working fluid (air) were sampled. Temperature measurements using a fast-response Pt100 sensor (PT100-SMD0805) were used for the temperature correction of the hot-wire data (for details, see [38]). The electrical inputs ( $i$ and $e$ ) were used to check and control the desired power input to the actuator.

The hot-wire probe calibration was completed within a velocity range of $0.15-50 \mathrm{~m} / \mathrm{s}$. The maximum relative uncertainty of a single velocity sample was less than $5 \%$ for velocities between 0.4 and $50 \mathrm{~m} / \mathrm{s}$. For very small velocities $(0.15-0.4 \mathrm{~m} / \mathrm{s})$ the highest uncertainty was $17.0 \%$. A more 
detailed description of the anemometer settings, probe calibration method, and uncertainty evaluation is available in [43].

The SJA cavity pressure measurements were performed using a homemade system based on a calibrated $1 / 4$ inch $(6.35 \mathrm{~mm})$ high-pressure microphone (type $40 \mathrm{BH})$ with a nominal sensitivity of $0.4 \mathrm{mV} / \mathrm{Pa}$. The microphone, with preamplifier (type 26AC), was embedded inside an enlarged PMMA block in the vicinity of the loudspeaker. The pressure readings along with the velocity profiles were used to evaluate the parameters $m_{\mathrm{n}}$ and $\xi$ for the lumped parameter model (see Equation (4) and Appendix A).

\section{Experimental Results}

\subsection{Frequency Characteristics}

In order to determine the optimum frequency at which the synthetic jet thrust was a maximum, the frequency characteristics were measured. Measurements were taken using a precision scale within the frequency range of $20-150 \mathrm{~Hz}$ for one selected power input: $1.02 \mathrm{~W}$. The resultant curves can be seen in Figure 2, where for each curve one peak indicates the maximum SJ thrust. The peak maxima are similar for each of the tested nozzle shapes. For $A, A B C$, and $A B C D$ nozzles, the same optimum frequency was found of $55 \mathrm{~Hz}$. In the case of the nozzle $A B$, the frequency with maximum thrust was $60 \mathrm{~Hz}$ and in case B it was $65 \mathrm{~Hz}$ (these frequencies are also summarized in Table 2). Note that all found optimum (or resonance) frequencies are very close to the natural frequency of the loudspeaker, which is around $68 \mathrm{~Hz}$, and were used in the following experiments, where the input power was varied.

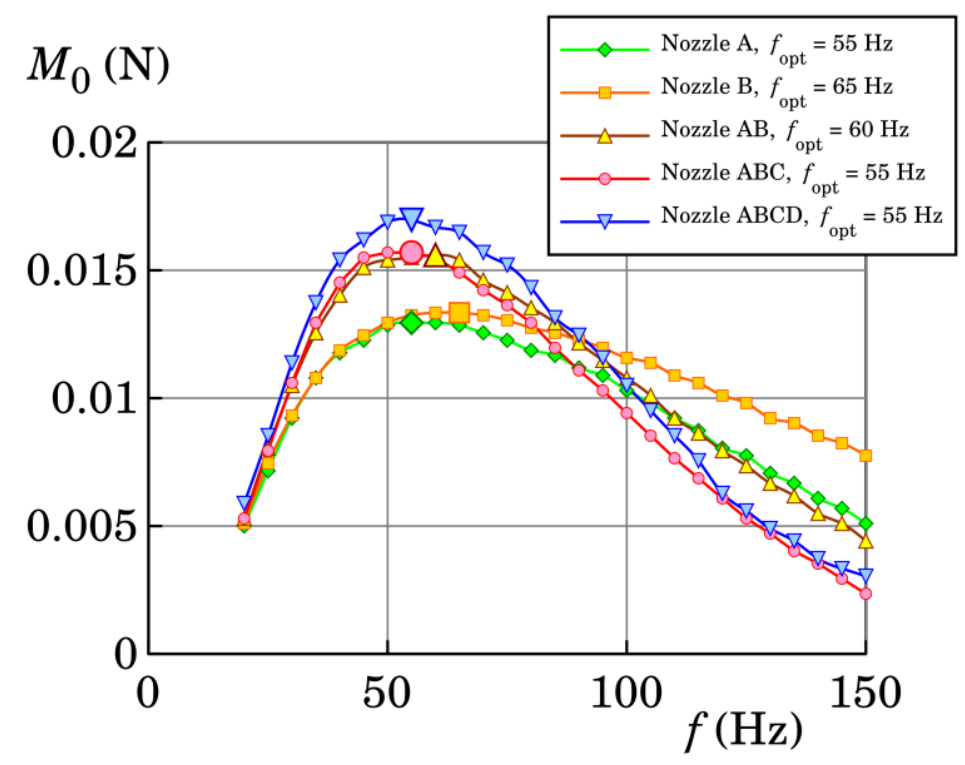

Figure 2. Frequency characteristics of SJA measured at $1.0 \mathrm{~W}$. The local maxima indicate the resonance frequencies for all particular nozzle cases; they are also summarized in Table 2.

Table 2. Identified resonance frequencies for particular nozzle cases.

\begin{tabular}{cc}
\hline Nozzle A & $55 \mathrm{~Hz}$ \\
Nozzle B & $65 \mathrm{~Hz}$ \\
Nozzle AB & $60 \mathrm{~Hz}$ \\
Nozzle ABC & $55 \mathrm{~Hz}$ \\
Nozzle ABCD & $55 \mathrm{~Hz}$ \\
\hline
\end{tabular}




\subsection{Synthetic Jet Thrust Measurement}

The synthetic jet thrust was measured for each nozzle at several input power levels defined in Table 1. The obtained dependencies of the SJ momentum flux on the input power, $P_{\mathrm{e}}$, are plotted in Figure 3a. As expected, the curves show monotonically increasing trends. For better comparison of the nozzles, Figure $3 b$ shows relative results with respect to reference nozzle A. With the help of Figure $3 b$, it can be concluded that the lowest momentum fluxes were achieved using nozzle A and the highest momentum fluxes were achieved with nozzle ABCD. Namely, nozzle ABCD caused a 29-33\% enhancement of the momentum flux in comparison with the reference nozzle A. It can be also seen that the resultant momentum fluxes for nozzles $A$ and $B$ were similar, as well as for nozzles $A B$ and $A B C$. The comparison of the curves in Figure $3 b$ proved that the auxiliary nozzle in the ABCD arrangement was successful in directing the radially dispersed momentum flux. The radial dispersion of the fluid was supposedly caused by the outer nozzle fillet; i.e., nozzle part C.

Apart from that, during the suction stroke, the auxiliary nozzle prevented fluid suction in the axial direction and supported the radial direction. This resulted in a significant increase in the SJ momentum flux.

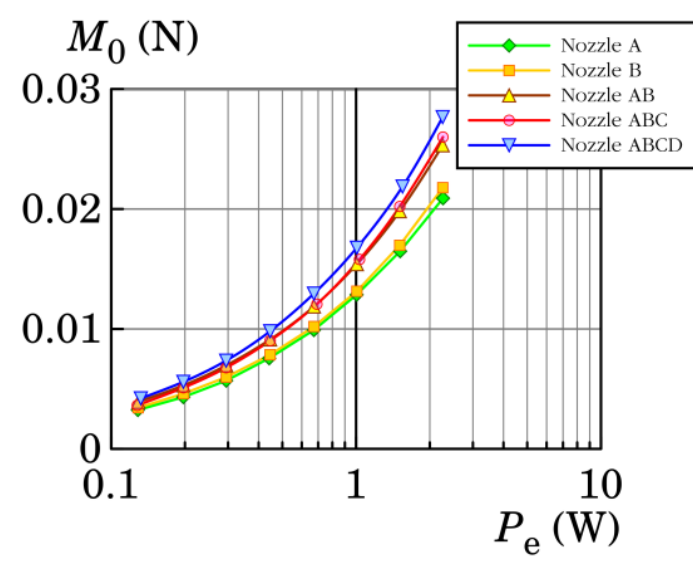

(a)

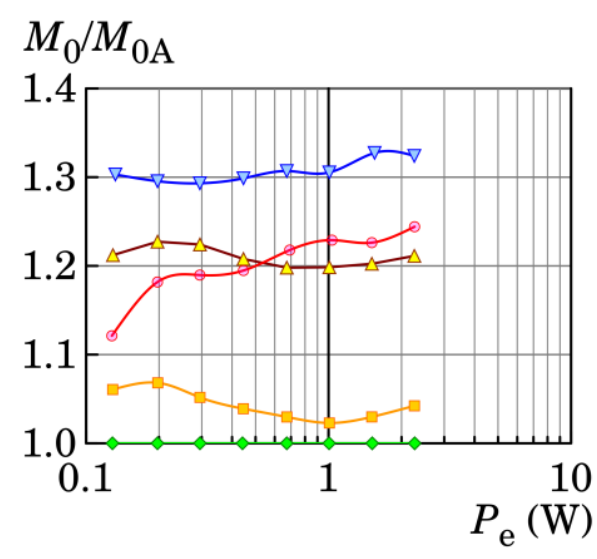

(b)

Figure 3. Results for experiments with precision scales performed at eight input power levels: (a) evaluated SJ thrust, (b) SJ thrust divided by the jet thrust values of the reference case-nozzle A.

\subsection{Measurement of Velocity Profiles}

The velocity profiles measured at $P_{\mathrm{e}}=0.68 \mathrm{~W}$ and at the optimal (resonant) frequencies, quantified in Figure 2, are shown for the tested nozzles in Figure 4a-e. It is well apparent that the shapes of velocity profiles of the nozzle A (Figure 4a) were markedly different than the profiles of the remaining nozzles. Namely, the boundary layer was much thicker than in the other cases. On the other hand, it was difficult to find a substantial difference in Figure $4 b-e$. One small difference is apparent for Figure $4 b$, which plots the results for nozzle B. The velocity profile approaching zero value seems to be slightly asymmetric in this case. This phenomenon can be caused by an unstable and sensitive boundary layer during a beginning of the suction stroke. Namely, a boundary layer separation from the nozzle sharp edge is developed and this effect is promoted by a divergent shape of B nozzle (divergent from the point of view of the suction flow towards the SJA cavity).

Comparing Figure $4 c-e$, another slight difference is noticeable for nozzle ABCD, where a bit higher velocities were measured than in remaining cases.

\subsection{Evaluation of $m_{n}$ and $\xi$}

Based on the measurements of cavity pressure variations and spatial integration of velocity profiles, the parameters $m_{\mathrm{n}}$ and $\xi$ were evaluated. The evaluation method is summarized in 
Appendix A and the results are shown in Figure 5a,b. The mass of the moving fluid inside and outside a nozzle, $m_{\mathrm{n}}$, is plotted here in a dimensionless form. Namely, it is related to the mass of air inside the nozzle, $m_{\mathrm{nn}}$. The ratio $m_{\mathrm{n}} / m_{\mathrm{nn}}$ is shown in Figure 5 a as a function of the dimensionless stroke length, $L_{0} / D_{\mathrm{n}}$, where the stroke length, $L_{0}$, was evaluated using Equations (1) and (3). The theoretical value of this ratio for a cylindrical hole is displayed with graphs in Figure 5 a and this value, $1+8 /(3 \pi)$, reasonably agrees with the results for the cylindrical nozzle A. Furthermore, it was found out that relative to their volumes the nozzles $(B, A B, A B C, A B C D)$ employed much less air into the motion than nozzle $\mathrm{A}$ and their ratios $m_{\mathrm{n}} / m_{\mathrm{nn}}$ were very similar. It is also noticeable that all evaluated ratios $m_{\mathrm{n}} / m_{\mathrm{nn}}$ had a very weak dependence on the dimensionless stroke length, $L_{0} / D_{\mathrm{n}}$ and, therefore, in a first approximation, they can be assumed constant.

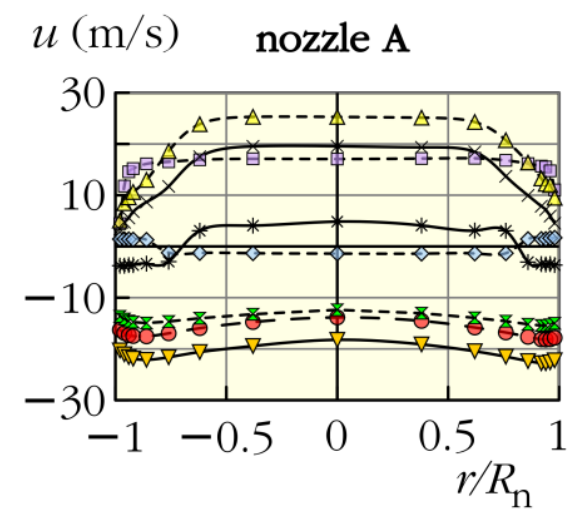

(a)

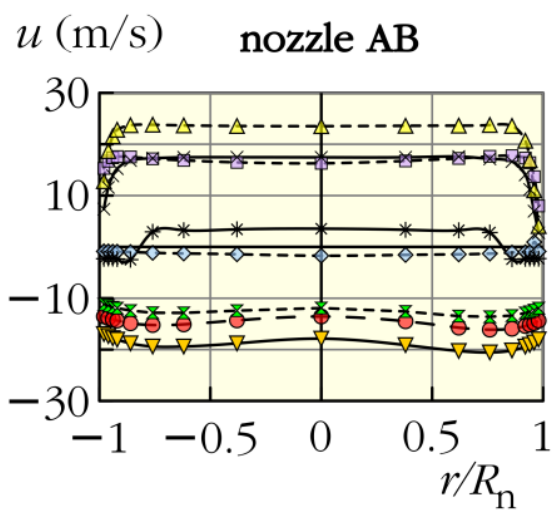

(c)

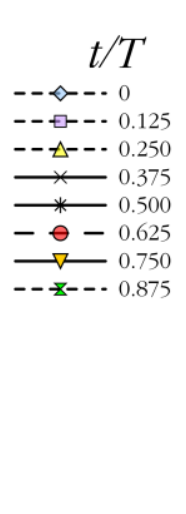

$u(\mathrm{~m} / \mathrm{s}) \quad$ nozzle B

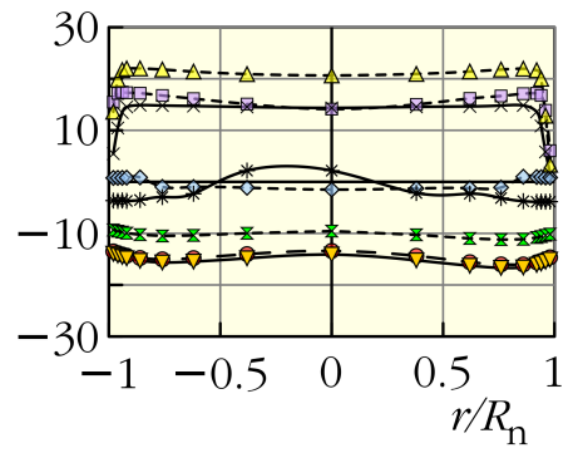

(b)

$u(\mathrm{~m} / \mathrm{s}) \quad$ nozzle $\mathrm{ABC}$

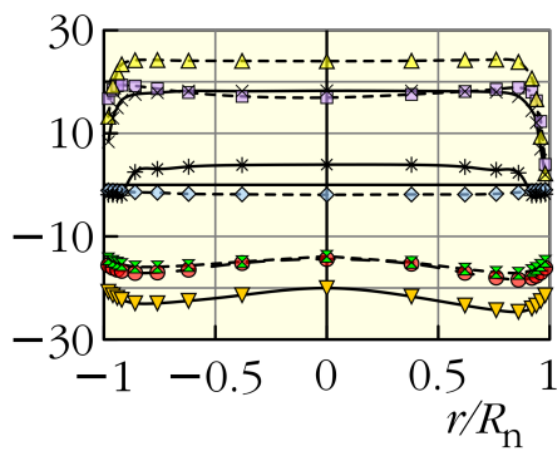

(d)

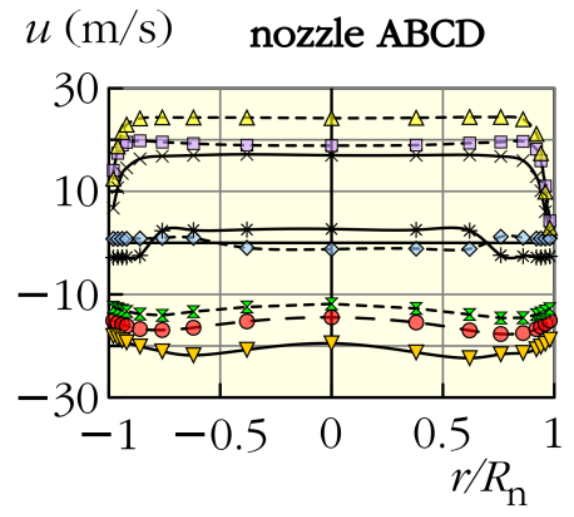

(e)

Figure 4. Velocity profiles measured by the hot-wire probe at the nozzle exits at input power of $0.68 \mathrm{~W}$ and the optimal (resonant) frequencies quantified in Figure 2. 
The pressure loss coefficients as functions of the dimensionless stroke length, $L_{0} / D_{\mathrm{n}}$, are displayed in Figure 5b. The results for nozzle A created a slightly increasing curve, which when compared to the results of Nani and Smith [32] showed a 15-27\% difference. This could have been caused by several factors including: different evaluation methods - the method in [32] did not include the optimization for $m_{n}$; different Reynolds number - as was mentioned at the beginning of the paper-the SJ is defined by the dimensionless stroke length and the Reynolds number. While the current Reynolds numbers were in the range of 2400-7100, the results from [32] were obtained at constant Reynolds number of 11,100 .

Surprisingly, the evaluated pressure loss coefficients for nozzle B were nearly identical to those found by Nani and Smith [32], as seen in Figure 5b. Apart from that, the pressure loss coefficient for nozzle B appeared to be nearly independent of dimensionless stroke length, $L_{0} / D_{\mathrm{n}}$. However, this was not true for the remaining cases $(A B, A B C$, and $A B C D)$, where a slightly increasing trend with a constant rate was well apparent. The lowest pressure loss coefficients $\approx 1.0$ were found for the configuration $\mathrm{ABCD}$, at the lowest stroke lengths.

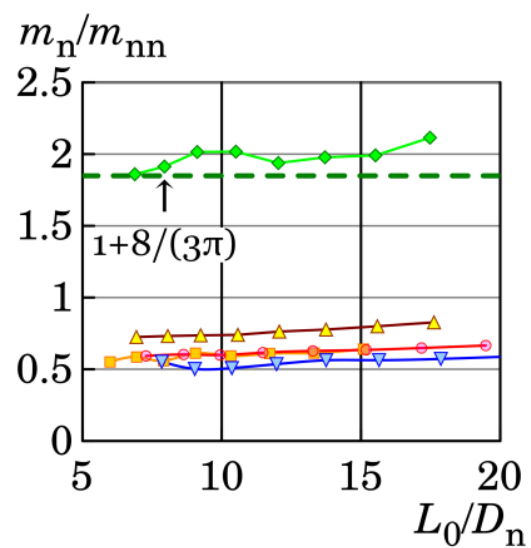

(a)

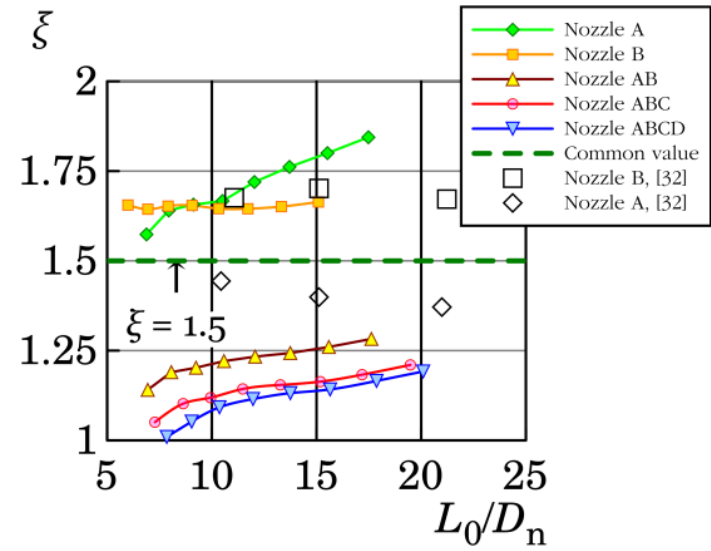

(b)

Figure 5. Evaluated parameters for lumped parameter model: (a) mass of the moving fluid inside the nozzle related to the fluid mass inside a nozzle, (b) pressure loss coefficient at cavity-nozzle-ambiance transition.

\section{Conclusions}

Five types of flanged nozzles for a SJA were tested. The first nozzle was a sharp-edged circular hole (nozzle A) and the second had a rounded shape (nozzle B). The third nozzle (AB) was a compound of both previous nozzles - its shape was rounded with a straight section at the nozzle exit. The next nozzle type had a special design with fillets at the inner and outer nozzle exits, with a small sharp step in the middle of the nozzle (case ABC). The last nozzle was assembled as the nozzle ABC but included an auxiliary outer nozzle placed slightly downstream from the nozzle ABC exit (the nozzle is denoted ABCD).

The investigated actuator that was based on a loudspeaker and worked at resonance was tested at several power inputs. The investigation of SJ momentum flux was based on the thrust measurements with a precision scale. It was found out that the highest momentum flux was achieved with original nozzle designs (ABC and ABCD) over the entire power input range. Namely, the nozzle ABCD caused a 29-33\% enhancement of the momentum flux in comparison with the reference (common, sharp-edged) nozzle A. The velocity profiles were measured using hot-wire anemometry. The comparison of the velocity profiles revealed that the profiles of nozzles $B, A B, A B C$, and $A B C D$ had very similar shapes, which differed from case $\mathrm{A}$, where thicker boundary layer was present.

Furthermore, a method for evaluating the moving fluid mass and pressure loss coefficient was introduced. The method was based on known velocity and pressure waveforms and on the momentum 
equation for fluid inside a nozzle. On the basis of the method, the moving fluid mass and the pressure loss coefficient were observed as functions of dimensionless stroke length. It was revealed that the ratio of the moving fluid mass and the mass of air volume inside the nozzle was nearly independent of the dimensionless stroke length.

Author Contributions: Conceptualization, J.K. and Z.T.; Funding acquisition, Z.T.; Investigation, J.K.; Methodology, J.K.; Project administration, Z.T.; Software, J.K.; Supervision, Z.T.; Visualization, J.K.; Writing—original draft, J.K.; Writing—review \& editing, Z.T.

Acknowledgments: We gratefully acknowledge the support of Grant Agency CR (project number 16-16596S) and the institutional support (RVO: 61388998).

Conflicts of Interest: The authors declare no conflict of interest.

\section{Nomenclature}

\begin{tabular}{ll}
$D$ & diameter, $\mathrm{m}$ \\
$e$ & electrical voltage, $\mathrm{V}$ \\
$f$ & driving frequency, $\mathrm{Hz}$ \\
$g$ & magnitude of the gravitational acceleration, $\mathrm{m} / \mathrm{s}^{2}$ \\
$i$ & electrical current, $\mathrm{A}$ \\
$L$ & length, $\mathrm{m}$ \\
$M$ & momentum flux, $\mathrm{N}$ \\
$m$ & mass, $\mathrm{kg}$ \\
$p$ & pressure, Pa \\
$P$ & input power, $\mathrm{W}$ \\
$r$ & radial coordinate, $\mathrm{m}$ \\
Re & Reynolds number, 1 \\
S & cross-sectional area, $\mathrm{m}^{2}$ \\
$T$ & time period, $\mathrm{s}$ \\
$t$ & time, $\mathrm{s}$ \\
$u$ & velocity, $\mathrm{m} / \mathrm{s}$ \\
$x$ & axial coordinate, $\mathrm{m}$ \\
$\rho$ & density, $\mathrm{kg} / \mathrm{m}^{3}$ \\
Subscripts & \\
0 & averaging in time and space \\
A & related to the nozzle A \\
$\mathrm{b}$ & barometric \\
c & cavity \\
$\mathrm{d}$ & diaphragm \\
$\mathrm{e}$ & electrical \\
$\mathrm{E}$ & extrusion stroke \\
$\mathrm{n}$ & nozzle \\
$\mathrm{nn}$ & related to nozzle internal \\
Superscripts & \\
$*$ & dimensionless \\
& \\
\hline & \\
\hline &
\end{tabular}

\section{Appendix A. Estimation of $m_{\mathbf{n}}$ and $\xi$}

The pressure loss coefficient, $\xi$, and moving fluid mass, $m_{\mathrm{n}}$, were obtained from the least-square-fit on the experimental data, similarly to Persoons [29], or to Persoons and O'Donovan [28], whose method was later used by Nani and Smith [32]. Unlike Persoons [29], who fits the parameters at different SJA driving frequencies, the momentum Equation (4) was used here as the criterion to be satisfied at each time instant of a measured velocity sample. The second difference from the Persoons method was that the current approach is not limited by assumption of harmonic shapes in the velocity and pressure waveform. The third difference was the fact that the nonlinear term of minor losses is not linearized here. These differences make the suggested method slightly more general. 
The proposed parameter fitting was based on the momentum equation for fluid motion inside the nozzle only. This is the second equation in Equation (4), which can be rewritten in the following matrix form:

$$
\left(\frac{\dot{u_{\mathrm{n}}}}{}, S_{\mathrm{n}} \rho \frac{\overline{u_{\mathrm{n}}}\left|\overline{\overline{u_{\mathrm{n}}}}\right|}{2}\right)\left(\begin{array}{c}
m_{\mathrm{n}} \\
\xi
\end{array}\right)=S_{\mathrm{n}} p_{\mathrm{c}}
$$

where the overlines above velocities denote spatial averaging. Equation (A1) can be extended for set of velocity, $u_{\mathrm{n}}$, and pressure, $p_{\mathrm{c}}$, samples acquired during the driving period as follows:

$$
\underbrace{\left(\begin{array}{cc}
\overline{u_{\mathrm{n}, 1}} & S_{\mathrm{n}} \rho \frac{\overline{u_{\mathrm{n}, 1}}}{2}\left|\overline{u_{\mathrm{n}, 1}}\right| \\
\vdots & \vdots \\
\frac{u_{\mathrm{n}, \mathrm{i}}}{2} & S_{\mathrm{n}} \rho \frac{\dot{u_{\mathrm{n}, \mathrm{i}}}}{2} \\
\vdots & \vdots \overline{u_{\mathrm{n}, \mathrm{i}}} \mid \\
\frac{u_{\mathrm{n}, \mathrm{m}}}{2} & S_{\mathrm{n}} \rho \frac{\overline{u_{\mathrm{n}, \mathrm{m}}}}{2}\left|\overline{u_{\mathrm{n}, \mathrm{m}}}\right|
\end{array}\right)}_{\mathbf{A}} \underbrace{\left(\begin{array}{c}
m_{\mathrm{n}} \\
\xi
\end{array}\right)}_{\mathbf{X}}=\underbrace{\left(\begin{array}{c}
S_{\mathrm{n}} p_{\mathrm{c}, 1} \\
\vdots \\
S_{\mathrm{n}} p_{\mathrm{c}, \mathrm{i}} \\
\vdots \\
S_{\mathrm{n}} p_{\mathrm{c}, \mathrm{m}}
\end{array}\right)}_{\mathbf{B}}
$$

where velocity $\overline{u_{\mathrm{n}, \mathrm{i}}}$, and pressure, $p_{\mathrm{c}, \mathrm{i}}$, samples are supplied here with index $\mathrm{i}$, from 1 to $\mathrm{m}$, where $\mathrm{m}$ is the number of samples in the measured velocity waveform. The velocity waveform was evaluated from velocity profile integration as follows:

$$
\overline{u_{\mathrm{n}}}=\frac{8}{D_{\mathrm{n}}^{2}} \int_{0}^{\frac{D_{\mathrm{n}}}{2}} u_{\mathrm{n}}(x=0, r, t) r d r .
$$

The velocity derivatives, $\frac{\dot{u_{\mathrm{n}, 1}}}{\text { }}$ in Equation (A2) were obtained using numerical derivation of the velocity waveform evaluated from Equation (A3).

The system of Equation (A2) is overdetermined and only an approximate solution can be found. Moore-Penrose matrix inversion allows us to find such solution that corresponds to the least-square-fitting. Hence, the parameters $\xi$ and $m_{\mathrm{n}}$, were solved as follows:

$$
\mathbf{X}=\left(\mathbf{A}^{\mathrm{T}} \cdot \mathbf{A}\right)^{-1} \cdot \mathbf{A}^{\mathrm{T}} \cdot \mathbf{B}
$$

where the index $\mathrm{T}$ denotes the operation for matrix transposition and the index -1 denotes the matrix inversion operation.

\section{References}

1. Smith, B.L.; Glezer, A. The formation and evolution of synthetic jets. Phys. Fluids 1998, 10, $2281-2297$. [CrossRef]

2. Cater, J.E.; Soria, J. The evolution of round zero-net-mass-flux jets. J. Fluid Mech. 2002, 472, 167-200. [CrossRef]

3. Lardeau, S.; Leschziner, M.A. The interaction of round synthetic jets with a turbulent boundary layer separating from a rounded ramp. J. Fluid Mech. 2011, 683, 172-211. [CrossRef]

4. Bernardini, C.; Carnevale, M.; Manna, M.; Martelli, F.; Simoni, D.; Zunino, P. Turbine blade boundary layer separation suppression via synthetic jet: An experimental and numerical study. J. Therm. Sci. 2012, 21, 404-412. [CrossRef]

5. Jabbal, M.; Zhong, S. Particle image velocimetry measurements of the interaction of synthetic jets with a zero-pressure gradient laminar boundary layer. Phys. Fluids 2010, 22, 063603. [CrossRef]

6. Sahni, O.; Wood, J.; Jansen, K.E.; Amitay, M. Three-dimensional interactions between a finite-span synthetic jet, a crossflow. J. Fluid Mech. 2011, 671, 254-287. [CrossRef]

7. Xia, X.; Mohseni, K. Transitional region of a round synthetic jet. Phys. Rev. Fluids 2018, 3, 011901. [CrossRef]

8. Chiatto, M.; Capuano, F.; de Luca, L. Numerical and experimental characterization of a double-orifice synthetic jet actuator. Meccanica 2018, 53, 2883-2896. [CrossRef]

9. Seo, J.H.; Cadieux, F.; Mittal, R.; Deem, E.; Cattafesta, L. Effect of synthetic jet modulation schemes on the reduction of a laminar separation bubble. Phys. Rev. Fluids 2018, 3, 033901. [CrossRef] 
10. Xia, Z.-X.; Luo, Z.-B. Physical factors of primary jet vectoring control using synthetic jet actuators. Appl. Math. Mech. 2007, 28, 907-920. [CrossRef]

11. Ben Chiekh, M.; Ferchichi, M.; Béra, J.-C.C. Aerodynamic flow vectoring of a wake using asymmetric synthetic jet actuation. Exp. Fluids 2012, 53, 1797-1813. [CrossRef]

12. Trávníček, Z.; Němcová, L.; Kordík, J.; Tesař, V.; Kopecký, V. Axisymmetric impinging jet excited by a synthetic jet system. Int. J. Heat Mass Transf. 2012, 55, 1279-1290. [CrossRef]

13. McGuinn, A.; Farrelly, R.; Persoons, T.; Murray, D.B. Flow regime characterisation of an impinging axisymmetric synthetic jet. Exp. Therm. Fluid Sci. 2013, 47, 241-251. [CrossRef]

14. Lee, A.; Yeoh, G.H.; Timchenko, V.; Reizes, J.A. Heat transfer enhancement in micro-channel with multiple synthetic jets. Appl. Therm. Eng. 2012, 48, 275-288. [CrossRef]

15. Zhang, Y.; Li, P.; Xie, Y. Numerical investigation of heat transfer characteristics of impinging synthetic jets with different waveforms. Int. J. Heat Mass Transf. 2018, 125, 1017-1027. [CrossRef]

16. Trávníček, Z.; Vít, T.; Tesař, V. Hybrid synthetic jets as the nonzero-net-mass-flux synthetic jets. Phys. Fluids 2006, 18, 081701. [CrossRef]

17. Trávníček, Z.; Tesař, V.; Kordík, J. Performance of synthetic jet actuators based on hybrid and double-acting principles. J. Vis. 2008, 11, 221-229. [CrossRef]

18. Kordík, J.; Trávníček, Z. Novel fluidic diode for hybrid synthetic jet actuator. J. Fluids Eng. 2013, 135, 101101. [CrossRef]

19. Kordík, J.; Broučková, Z.; Trávníček, Z. Impinging jet-based fluidic diodes for hybrid synthetic jet actuators. J. Vis. 2015, 18, 449-458. [CrossRef]

20. Gallas, Q.; Holman, R.; Nishida, T.; Carroll, B.; Sheplak, M.; Cattafesta, L. Lumped element modeling of piezoelectric-driven synthetic jet actuators. AIAA J. 2003, 41, 240-247. [CrossRef]

21. Kim, B.H.; Williams, D.R.; Emo, S.; Acharya, M. Modeling pulsed-blowing systems for flow control. AIAA J. 2005, 43, 314-325. [CrossRef]

22. Kordík, J.; Trávníček, Z. Axisymmetric synthetic jet actuators with large streamwise dimensions. AIAA J. 2013, 51, 2862-2877. [CrossRef]

23. De Luca, L.; Girfoglio, M.; Coppola, G. Modeling and experimental validation of the frequency response of synthetic jet actuators. AIAA J. 2014, 52, 1733-1748. [CrossRef]

24. Sharma, R.N. Fluid-dynamic-based analytical model for synthetic jet actuation. AIAA J. 2007, 45, 1841-1847. [CrossRef]

25. Chiatto, M.; Capuano, F.; Coppola, G.; de Luca, L. LEM characterization of synthetic jet actuators driven by piezoelectric element: A review. Sensors 2017, 17, 1216. [CrossRef] [PubMed]

26. Broučková, Z.; Trávníček, Z. Visualization study of hybrid synthetic jets. J. Vis. 2015, 18, 581-593. [CrossRef]

27. Mohseni, K.; Mittal, R. Synthetic Jets: Fundamentals and Applications; CRC Press, Taylor \& Francis: Boca Raton, FL, USA, 2015.

28. Persoons, T.; O'Donovan, T.S. A pressure-based estimate of synthetic jet velocity. Phys. Fluids 2007, 19, 128104. [CrossRef]

29. Persoons, T. General reduced-order model to design and operate synthetic jet actuators. AIAA J. 2012, 50, 916-927. [CrossRef]

30. Kordík, J.; Trávníček, Z. Optimal diameter of nozzles of synthetic jet actuators based on electrodynamic transducers. Exp. Therm. Fluid Sci. 2017, 86, 281-294. [CrossRef]

31. Kordík, J.; Broučková, Z.; Vít, T.; Pavelka, M.; Trávníček, Z. Novel methods for evaluation of the Reynolds number of synthetic jets. Exp. Fluids 2014, 55, 1757. [CrossRef]

32. Nani, D.J.; Smith, B.L. Effect of orifice inner lip radius on synthetic jet efficiency. Phys. Fluids 2012, 24, 115110. [CrossRef]

33. Kordík, J.; Trávníček, Z.; Timchenko, V.; Ismail, N.A. The predominant effect of stroke length on velocity profiles at the exit of axisymmetric synthetic jet actuators. Int. J. Heat Fluid Flow 2017, 66, 197-208. [CrossRef]

34. Tesař, V.; Kordík, J. Quasi-similarity model of synthetic jets. Sens. Actuators A Phys. 2009, 149, $255-265$. [CrossRef]

35. Tesař, V.; Kordík, J. Time-mean structure of axisymmetric synthetic jets. Sens. Actuators A Phys. 2010, 161, 217-224. [CrossRef]

36. Lee, C.Y.; Goldstein, D.B. Two-dimensional synthetic jet simulation. AIAA J. 2002, 40, 510-516. [CrossRef] 
37. Rylatt, D.I.; O’Donovan, T.S. Heat transfer enhancement to a confined impinging synthetic air jet. Appl. Therm. Eng. 2013, 51, 468-475. [CrossRef]

38. Kordík, J.; Trávníček, Z. Non-harmonic excitation of synthetic jet actuators based on electrodynamic transducers. Int. J. Heat Fluid Flow 2018, 73, 154-162. [CrossRef]

39. Trávníček, Z.; Fedorchenko, A.I.; Wang, A.-B. Enhancement of synthetic jets by means of an integrated valve-less pump, Part I: Design of the actuator. Sens. Actuator A Phys. 2005, 120, 232-240. [CrossRef]

40. Kooijman, G.; Ouweltjes, O. Finite difference time domain electroacoustic model for synthetic jet actuators including nonlinear flow resistance. J. Acoust. Soc. Am. 2009, 125, 1911-1918. [CrossRef] [PubMed]

41. Trávníček, Z.; Broučková, Z. A synthetic jet issuing from a bio-inspired actuator with an oscillating nozzle lip. J. Fluids Eng. 2018, 140, 101104. [CrossRef]

42. Kordík, J.; Trávníček, Z. Integral quantities of axisymmetric synthetic jets evaluated from a direct jet thrust measurement. Flow Turbul. Combust. 2018, submitted.

43. Kordík, J. Theoretical and Experimental Analysis of Synthetic and Hybrid Synthetic Jet Actuators. Ph.D. Thesis, Czech Technical University, Prague, Czech Republic, 2011.

(C) 2018 by the authors. Licensee MDPI, Basel, Switzerland. This article is an open access article distributed under the terms and conditions of the Creative Commons Attribution (CC BY) license (http://creativecommons.org/licenses/by/4.0/). 